\title{
Analisa Desain Aplikasi Inventory Alat Pada Cabang Olahraga Federasi Panjat Tebing Indonesia (Fpti) Kota Tangerang Menggunakan Mern(Mongodb, Express, React \& Node.Js)
}

\author{
Mukti Budiarto ${ }^{1}$ \\ Dedeh Supriyanti ${ }^{2}$ \\ Abdullah $^{3}$ \\ ${ }^{1 \& 2}$ Progam Studi Teknik Informatika, Fakultas Sains dan Teknologi, Universitas Raharja \\ ${ }^{3}$ Program Studi Sistem Informasi, Fakultas Sains dan Teknologi,Universitas Raharja \\ e-mail: ${ }^{1}$ Mukti@raharja.info, ${ }^{2}$ Dedeh@ @raharja.info, Abdullah@ $\underline{\text { raharja.info }}{ }^{3}$
}

\begin{abstract}
Abstrak
Federasi Panjat Tebing Indonesia (FPTI) Kota Tangerang juga ingin memberikan pelayanan terbaik dalam sistem peminjaman alat yang masih manual, sehingga kepala bidang logistik masih menemukan kendala saat suatu alat ingin di data kembali, karena peminjaman alat itu sendiri masih meggunakan form kertas yang harus diisi manual setiap ada yang ingin menggunakannya. Sistem yang terkomputerisasi memudahkan kepala bidang logistik dalam mencari informasi pendataan, pencarian, dan membuat laporan akhir. Bidang logistik memiliki tugas untuk mengelola semua hal yang berhubungan dengan inventory mulai dari peminjaman alat, sampai mendata alat-alat yang baru. Metode yang digunakan adalah Observasi, Interview, dan Literature Review untuk menghasilkan sebuah penelitian yang terarah sesuai keadaan yang ada. Hasil yang diperoleh dari penelitian ini adalah sebuah sistem yang manual dapat dirubah dalam prosesnya, sehingga kedepannya dapat menjadi sistem yang terkomputerisasi dan dapat digunakan dengan efektif dan efesien.
\end{abstract}

Kata kunci-Inventory, peminjaman alat, MERN

\begin{abstract}
The Indonesian Rock Climbing Federation of Tangerang City also wants to provide the best service in a manual tool borrowing system, so the head of the logistics sector still encounters obstacles when a tool wants to be returned to data, because borrowing the tool itself still uses paper forms that must be filled out manually. anyonewhowants to use it. The computerized system makes it easier for the head of the logistics sector to find information on data collection, search, and make final reports. The logistics sector has the task of managing all things related to inventory, from borrowing tools, to registering new tools. The method used is Observation, Interview, and Literature Review to produce a research that is directed according to the existing circumstances. The results obtained from this study are a manual system that can be changed in the process, so that in the future it can become a computerized system and can be used effectively andefficiently.
\end{abstract}

\section{Key words-Inventory, tool loan, MERN}




\section{PENDAHULUAN}

Maju dan berkembang merupakan tujuan utama setiap organisasi atau perusahaan.Tujuan tersebut mendorong perusahaan selalu mengikuti atau memperbaharui teknologi sistem informasinya.Kemajuan teknologi sistem informasi tidak dapat dipungkiri dan memaksa suatu organisasi/perusahaan untuk terus mengikutinya.Sistem informasi adalah suatu sistem didalam organisasi yang mempertemukan kebutuhan pengelohan transaksi harian, mendukung operasi, bersifat manajerial dan kegiatan strategi serta menyediakan pihak luar tertentu dengan laporan laporan yang diperlukan sistem informasi merupakan kombinasi teratur dari orang-orang hardware, software, jaringan komunikasi dan sumber daya data untuk mengumpulkan data serta menyebarkan informasi dalam organisasi[1].Ketersediaan informasi yang optimal menjadi kelebihan tersendiri yang harus dimiliki oleh setiap organisasi/perusahaan..

Teknologi sistem informasi sangat penting dan tidak dapat diabaikan begitu saja.Sistem informasi inilah sebagai media informasi untuk mendukung para eksekutor dan pimpinan organisasi/perusahaan dalam mengambil keputusan yang wajar dan bijak.

Federasi Panjat Tebing Indonesia (FPTI) Kota Tangerang juga ingin memberikan pelayanan terbaik dalam sistem peminjaman alat yang masih manual, sehingga kepala bidang logistik masih menemukan kendala saat suatu alat ingin di data kembali, karena peminjaman alat itu sendiri masih meggunakan form kertas yang harus diisi manual setiap ada yang ingin menggunakannya. Inventory atau biasa disebut dengan pengarsipan adalah barang-barang yang disimpan sementara untuk digunakan pada masa atau periode yang akandatang [2].Sistem yang terkomputerisasi memudahkan kepala bidang logistik dalam mencari informasi pendataan, pencarian, dan membuat laporan akhir.

\section{METODE PENELITIAN}

\subsection{Teknik Pengumpulan Data}

Teknik pengumpulan data yang digunakan dalam penelitian ini ada empat, yaitu:

1. Metode Observasi (Pengamatan)

Dengan melakukan observasi penulis mendatangi langsung tempat penelitian, yaitu di Federasi Panjat Tebing Indonesia (FPTI) Kota Tangerang.

\section{Metode Wawancara}

Dengan melakukan interview atau wawancara langsung dengan kepala bidang logistik FPTI Kota Tangerang, penulis mendapatkan begitu banyak data dan informasi terhadap masalah dan kendala yang dialami selama ini..

\section{Studi Kepustakaan}

Studi pustaka sangat berperan penting dalam mendukung kelancaran KKP, karena sumber historical data, salah satunya bersumber dari studi pustaka.Dengan studi pustaka kita dapat menambah wawasan berpikirkita.

\subsection{Metode Perancangan}

Dalam penelitian ini menggunakan metode perancangan Unified Modelling Language yang disingkat UML.UML Merupakan sebuah standar bahasa pemodelan yang digunakan untuk menggambarkan sebuah sistem informasi yang akan dibangun. UML dapat bersifat platform- independent atau platform-spesific tergantung pada pilihan perancangansistem[3] 


\subsection{Literature Review}

Berikut ini adalah penelitian yang telah dilakukan dan memiliki korelasi yang searah dengan penelitian yang akan dibahas dalam laporan ini, antara lain :

1. Penelitian yang dilakukan oleh Usman Ependi (2018) yang berjudul "Pemodelan Sistem Informasi Monitoring Inventory Sekretariat Daerah Kabupaten MusiBanyuasin"proses penelitian pemodelan sistem informasi monitoring inventory sekretariat daerah Kabupaten Musi Banyuasin sesuai dengan metode pelaksanaan penelitian maka dapat disimpulkan bawah pemodelan dilakukan menggunakan notasi UML dengan tiga kategori diagram yaitu structure diagram digambarkan dengan class diagram, behaviordiagram gambarkan dengan use case diagram dan interaction diagram digambarkan dengan sequence diagram[4].

2. Penelitian yang dilakukan oleh Siti Monalisa, dkk (2018) yang berjudul "Rancang Bangun Sistem Informasi Inventory Obat Pada Rumah Sakit Jiwa Tampan Berbasis Web" Berdasarkan hasil penelitian dapat disimpulkan sistem informasi inventory obat untuk Membantu dalam pengecekan stok obat yang masuk ataupun keluar, peringatan obat stok, peringatan kadaluarsanya obat sehingga tidak terjadi kekeliruan dalam pencatatan stok dan pemesanan dari gudang ke supplier. Selain itu juga dapat memudahkan pegawai melihat perkembangan inventory obat yang dilakukan setiap transaksi sehingga meningkatkan efektivitas dan efisiensi kerja terutama dalam menghasilkan laporan [5].

\section{HASIL DAN PEMBAHASAN}

Untuk menganalisa sistem yang berjalan, penelitian ini menggunakan program Unified Modelling Language (UML) untuk menggambarkan prosedur dan proses yang berjalan saat ini. Pada analisa ini terdiri dari beberapa prosedur sistem yang sedang berjalan diantaranya yaitu :

a. Pelatih datang untuk meminjamalat

b. Bidang logistik memberikan form untuk meminjamalat

c. Pelatih mengisi form alat apa saja yang dipinjam, lalu menyerahkan kembali ke bidanglogistik

d. Bidang logistik mengambil alat yang dipinjam, lalu diserahkan ke pelatih

e. Pelatih menerima alat dari bidang logistik, lalu diserahkan keatlet

f. Atlet menerima alat untuklatih.

\subsection{Use Case Diagram}

Berikut adalah use case diagramyang sedang berjalan pada Federasi Panjat Tebing Kota Tangerang: 
ISSN: 2461-1409

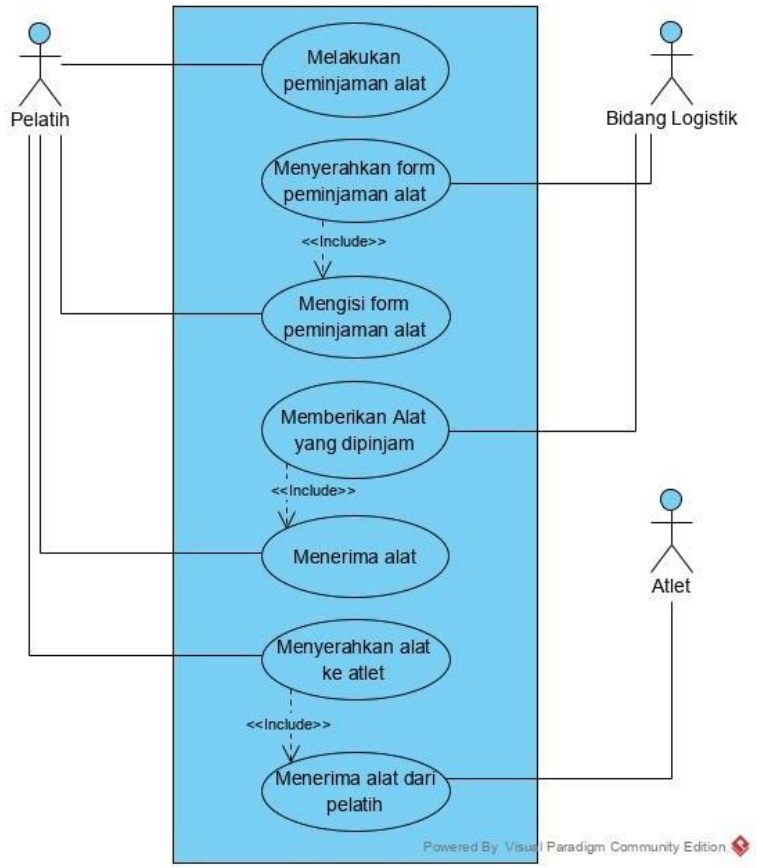

Gambar 1 Use Case Diagram Sistem yang sedang berjalan

Berdasarkan gambar 1 Use Case Diagram Sistem yang sedang berjalan terdapat :

a. Bidang logistik memberikan form untuk meminjamalat

b. sistem yang berjalan pada Federasi Panjang Tebing Kota Tangerang

c. 3 aktor yang melakuan kegiatan : Pelatih, Bidang Logistik, dan Atlet

d. 7 Use Case yang dilakukan oleh aktor diantaranya

\subsection{Activity Diagram}

Berikut adalah activity diagram yang sedang berjalan pada Federasi Panjang Tebing Kota Tangerang : 


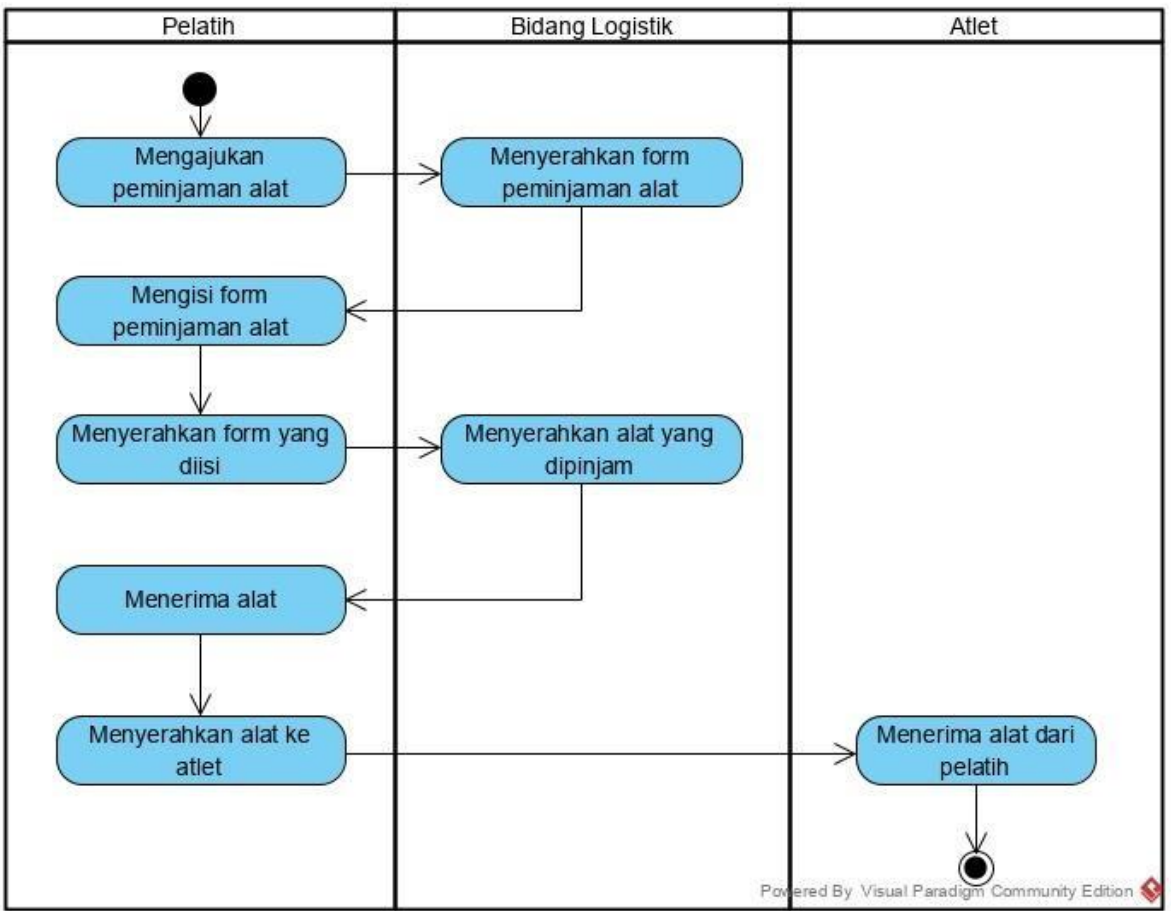

Gambar 2 Activity Diagram yang sedang berjalan

Berdasarkan gambar 2 Activity Diagram Sistem yang sedang berjalan terdapat :

a. 1 initial node objek yang diawali

b. Al node, objek yang diawali

c. 8 action, state dari sistem yang mencerminkan eksekusi dari suatu aksi

d. 1 final state, objek yang diakhiri.

\subsection{Sequence Diagram}

Berikut adalah Sequence diagram yang sedang berjalan pada Federasi Panjang Tebing Kota Tangerang :

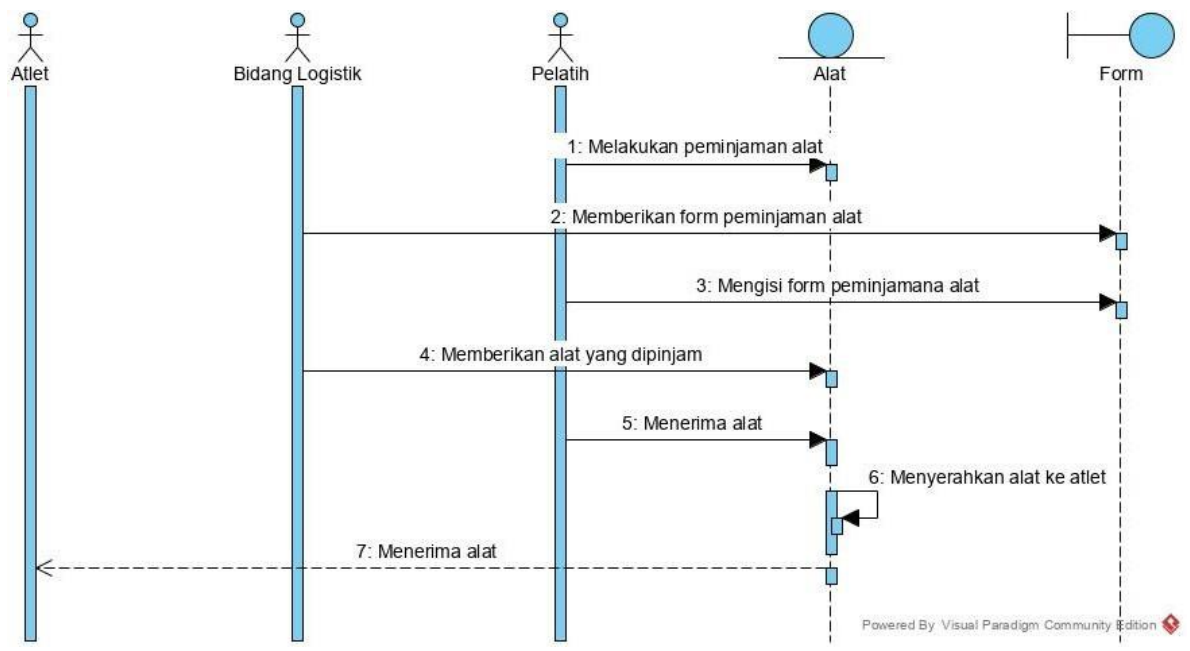

Gambar 3 Sequence Diagram yang sedang berjalan 
Berdasarkan gambar 3Sequence DiagramSistem yang sedang berjalan terdapat :1 initial node objek yang diawali

a. 3 aktor yang melakukan kegiatan diantaranya: Pelatih, Bidang Logistik, dan Atlet.

b. 7 message sepesifikasi dari komunikasi antar objek yang memuat informasi-informasi tentang aktifitas yang terjadi.

\subsection{Konfigurasi Sistem Berjalan}

Dalam menganalisa sistem ini guna menyelesaikan penelitian, Penulis menggunakan komputer dengan konfigurasi sebagai berikut :

1. Perangkat Keras (Hardware)
a. Processor : AMD Ryzen 7 3700U
b. Monitor : 14.0 ',
c. RAM : 8 GB DDR 4
d. Mouse : Logitech
e. SSD : 512 GB

2. Perangkat Lunak (Software)
a. Windows 10
b. Ms. Office
c. Visual Paradigm

3. Brainware :

Untuk menggunakan sistem dapat dilakukan oleh user

3.5. Permasalahan yang dihadapi dan alternatif pemecahan masalah

1. Permasalahan yang dihadapi

Sistem inventory yang ada sekarang kurang tertata penyimpanan formnya yang sudah diisi, sehingga menyebabkan hilangnya data alat apa saja yang sudah dipinjam, masih bisa dikatakan bahwa proses tersebut masih belum optimal. Pada proses yang berjalan terlihat bahwamasalah yang sering muncul dari proses tersebut disebabkan belum adanya sistem informasi yang dirancang khusus untuk digunakan sebagai inventory yang terkomputerisasi.

\section{Alternatif Pemecahan Masalah}

Setelah meneliti dan mengamati dari permasalahan yang ada pada sistem yang sedang berjalan, Adapun alternatif pemecahan masalah yang peneliti usulkan adalah sebagai berikut :

a. Federasi Panjang Tebing Kota Tangerang harus menerapkan sistem informasi manajemen pelatihan yangterkomputerisasi.

b. Membantu Bidang logistik dan si peminjam alat mudah dalam melakuakan prosesinventory.

c. Merancang Sistem informasi berbasis web yang terintegrasi agar mempermudah bidang logistik untuk meyimpan data dengan aman danefisien. 
3.6. Prototype Program

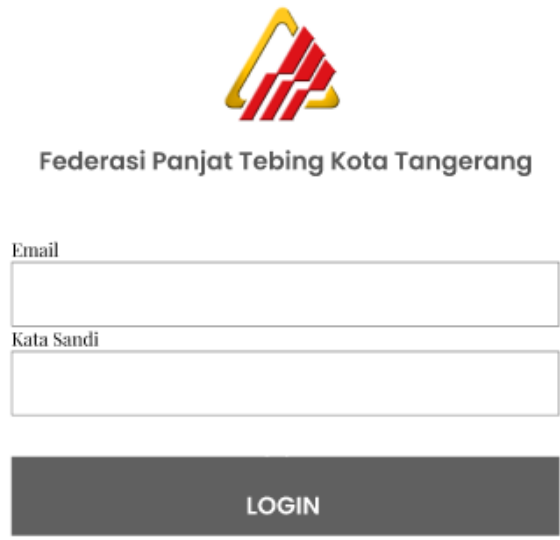

Gambar 4.1 Tampilan Halaman Login User

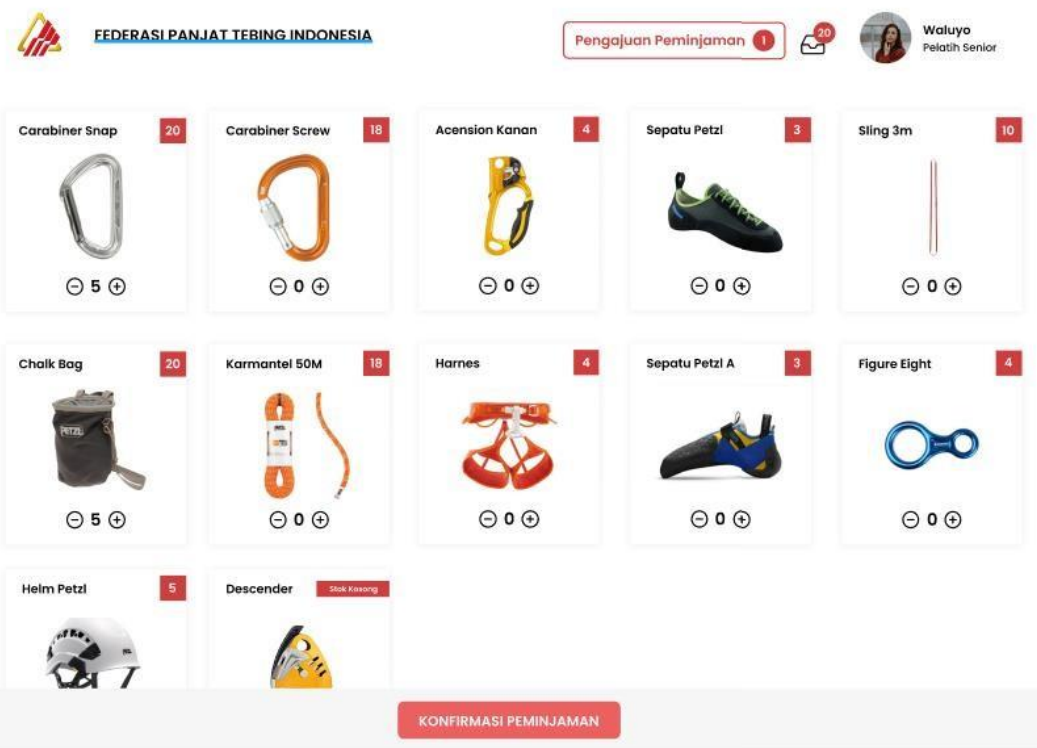

Gambar 4.2 Tampilan Halaman Display Alat User

\section{Pengajuan Peminjaman}

\begin{tabular}{|c|c|c|c|c|c|c|}
\hline NDEATN & Kabid & Tanggal & Durasi & Jumlah & Status & Action \\
\hline$\# 1$ & Admin & 10 Juli 2021 & 3 Hari & 5 barang & Barang Kurang & Terima \\
\hline
\end{tabular}

Gambar 4.3 Tampilan Halaman Pengajuan Pinjaman User 
ISSN: 2461-1409

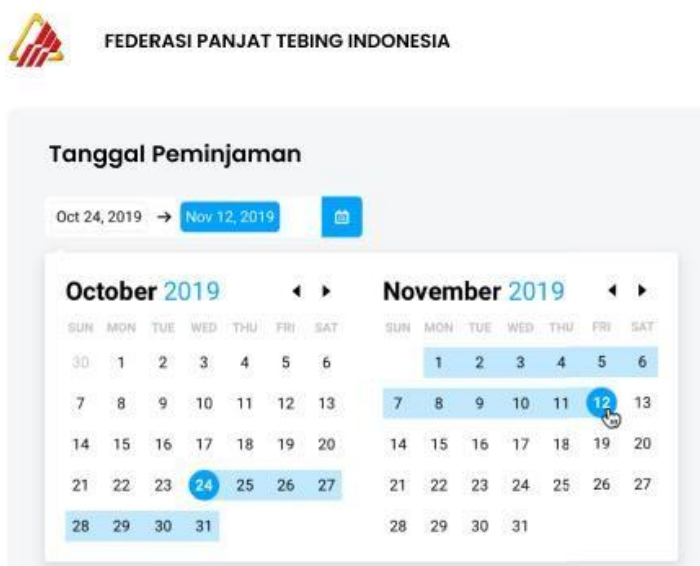

Gambar 4.4 Tampilan Halaman

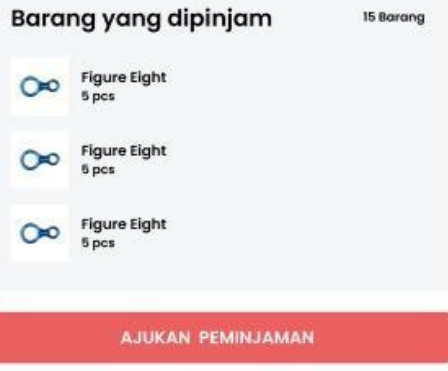

FEDERASI PANJAT TEBING INDONESIA

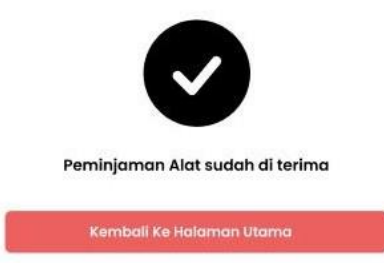

Gambar 4.5 Tampilan Halaman Peminjaman Terkonfirmasi User 


\section{Federasi Panjat Tebing Kota Tangerang}

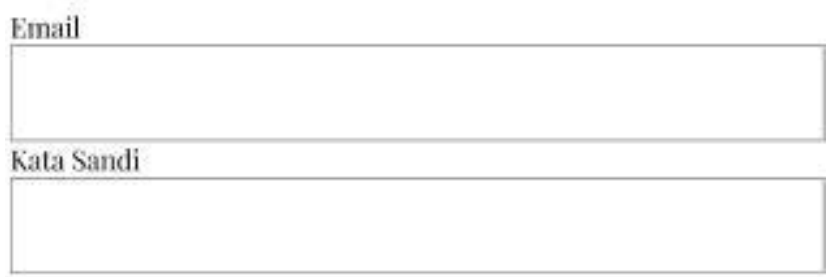

LOGIN

Gambar 4.6 Tampilan Halaman Login Admin

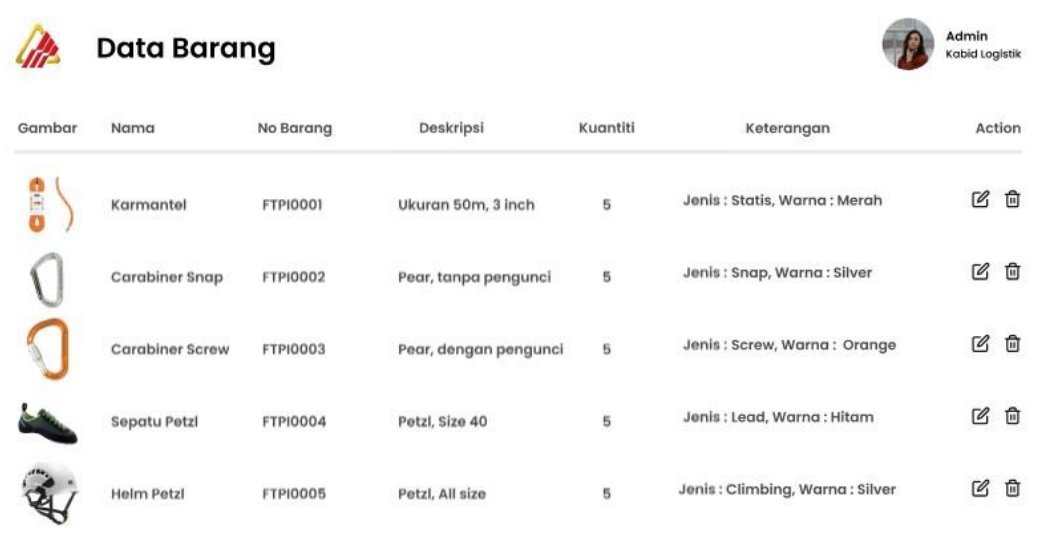

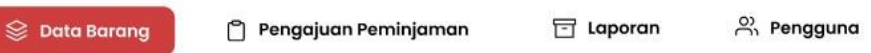

Gambar 4.7 Tampilan Halaman Data Barang Admin 
ISSN: 2461-1409

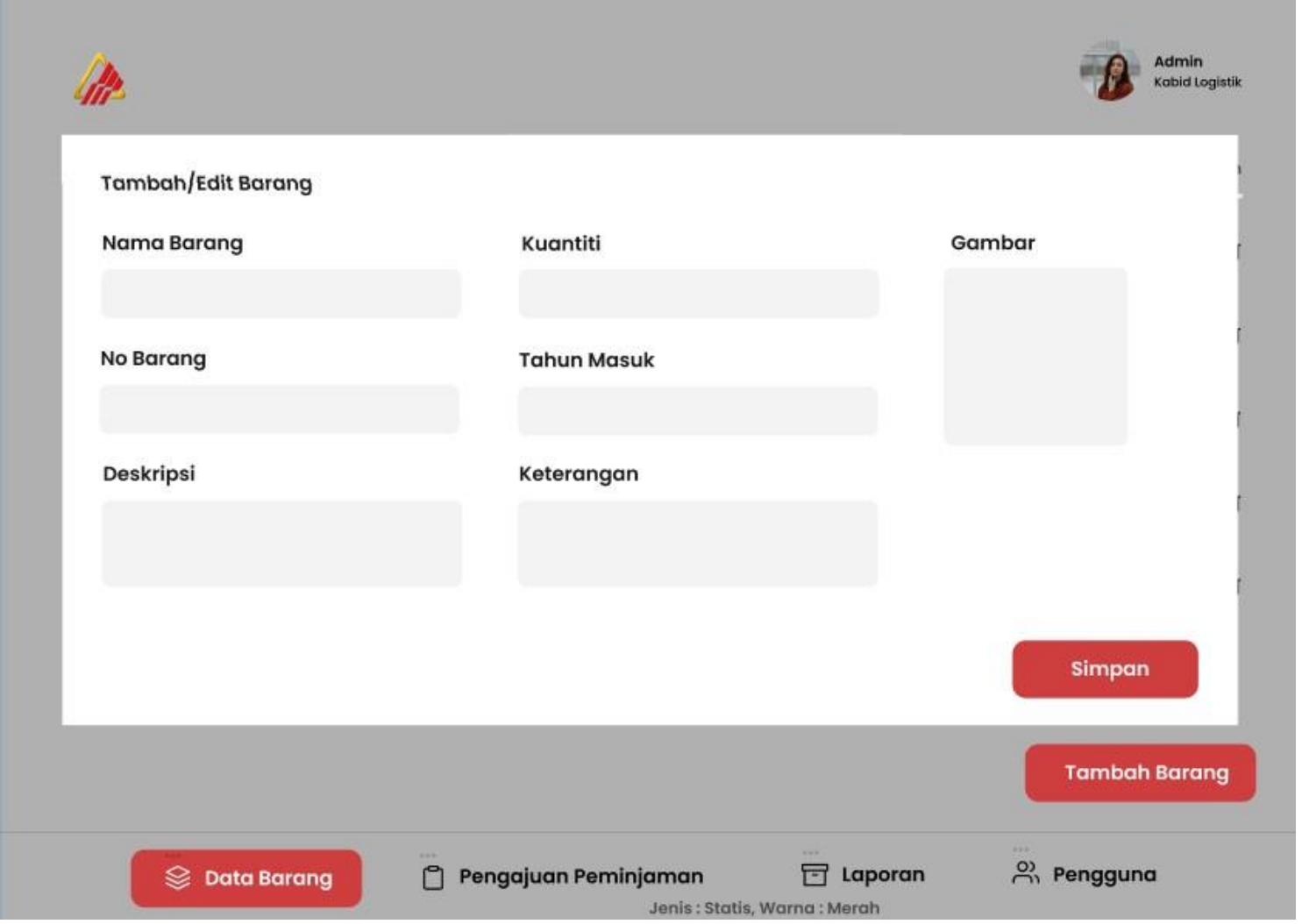

Gambar 4.8 Tampilan Halaman Tambah/Edit Barang Admin

\section{Pengajuan Peminjaman}

\begin{tabular}{|c|c|c|c|c|c|c|}
\hline nother & Peminjam & Tanggal & Durasi & Jumlah & Status & Action \\
\hline$\# 1$ & Wahyudi & 10 Juli 2021 & 3 Hari & 5 barang & Terkonfirmasi & $\Theta$ \\
\hline \#2 & Abdullah & 15 Juli 2021 & 1 Hari & 8 barang & Terkonfirmasi & 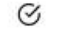 \\
\hline
\end{tabular}

Data Barang $\quad$ Pengajuan Peminjaman

Gambar 4.9 Tampilan Halaman Pengajuan Pinjaman Admin 
ISSN: 2461-1409

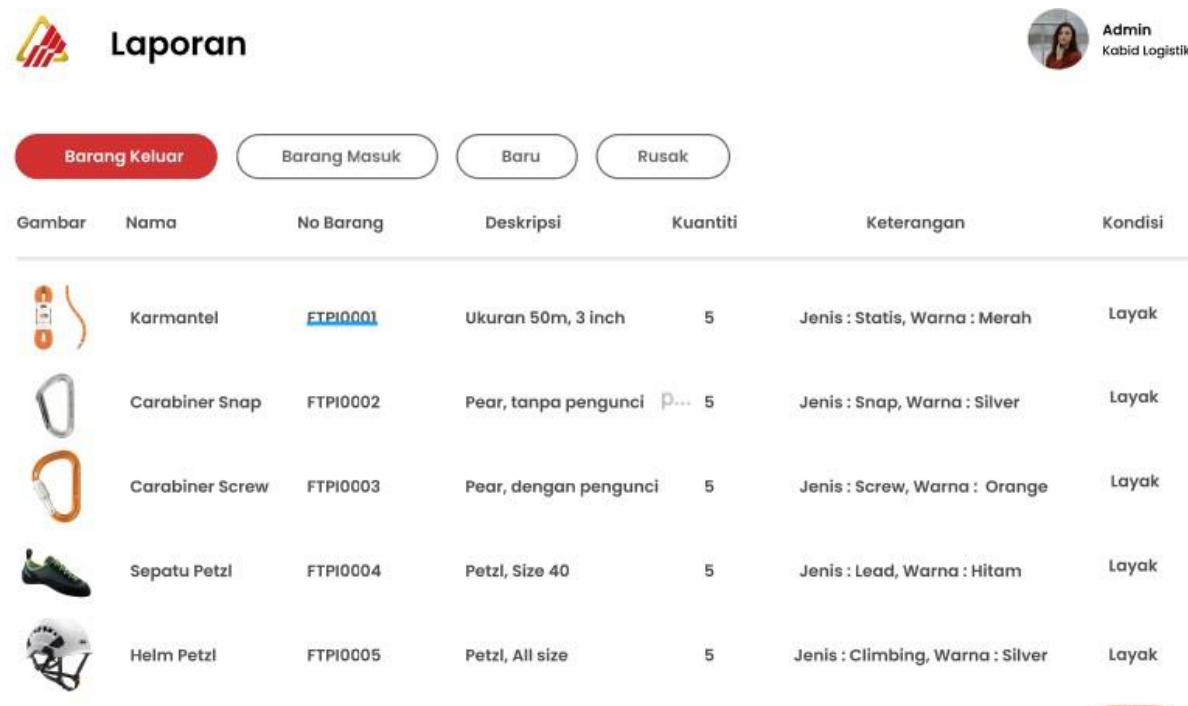

$\triangleq$ Data Barang $\quad \square$ Pengajuan Peminjaman $\quad \stackrel{\square}{\circ}$ Laporan Penguna

Gambar 4.10 Tampilan Halaman Laporan Admin

\begin{tabular}{|c|c|c|c|c|c|c|}
\hline Gambar & Nama & No Anggota & Jabatan & Alamat & Status & Action \\
\hline & Muhamad Virdaus & FTP12019.01 & Coach Speed & Kota Tangerang & Aktif & [0 向 \\
\hline & Wahyudi & FTPI2019.02 & Coach Speed & Kota Tangerang & Aktif & [9 旬 \\
\hline & Dwi Aprianto & FTPI2019.03 & Coach Lead & kab. Tangerang & Aktif & 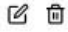 \\
\hline & Abdullah & FTPI2019.04 & Coach Speed & Tangerang Selatan & Aktif & [0. 同 \\
\hline
\end{tabular}
$\approx$ Data Barang
$\bigcirc$ Pengajuan Peminjaman
I Laporan
$\stackrel{\circ}{\cap}$ Pengguna

Gambar 4.11 Tampilan Halaman Data Pengguna Admin 


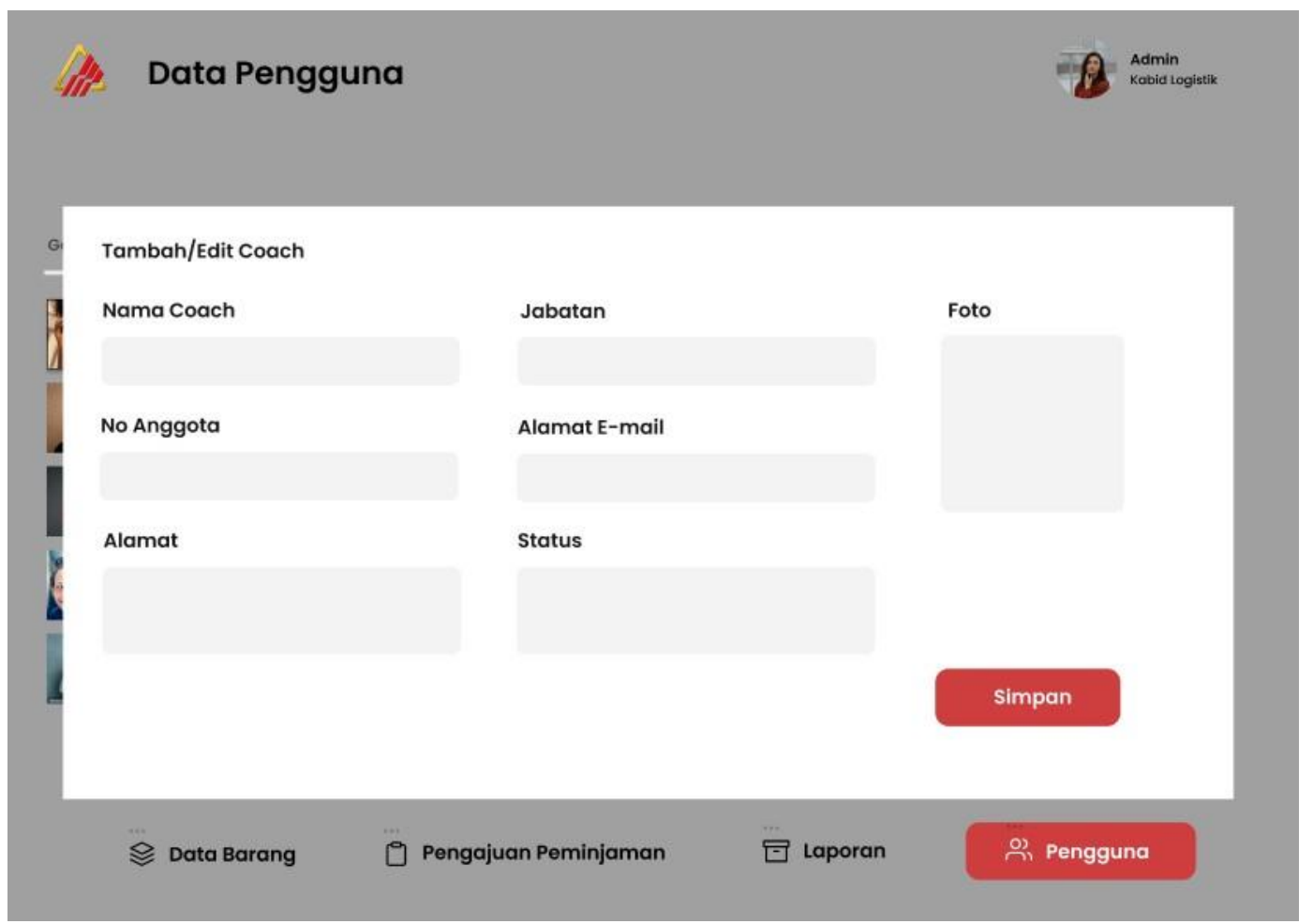

Gambar 4.12 Tampilan Halaman Tambah/Edit Pelatih Admin

\section{KESIMPULAN}

Berdasarkananalisis yang dilakukan dapat disimpulkan sebagai berikut:

1. Sistem yang berjalan saat ini masih manual dalam kesehariannya yaitu mengunakan form untuk melakukan peminjamanalat.

2. Kelemahan sistem yang berjalan saat ini sangat memungkinkan untuk kehilangan data alat apasaja yang sedang dipinjam, dikarenakan penggunaanya masih mengunakan form yang bisa saja hilang atauterselip.

3. Tidak dapat dipungkiri jika dirancang sistem yang terkomputerisasi dapat membantu bidang logistik bekerja dengan lebih efektif dan efisien dalam melakukan pendataaninventory.

\section{SARAN}

Dalam kesempatan ini penulis mencoba memberikan masukan atau saran yang mungkin bermanfaat untuk pengembangan pada Federasi Panjat Tebing Kota Tangerang sebagai berikut:

1. Perlunya perubahan dalam sistem yang berjalan saat ini agar lebih aman menyimpan datainventory.

2. Perlunya sistem yang terkomputerisasi pada inventory peminjaman alat agar lebih efektif danefisien.

3. Perlunya tatanan ulang dalam prosedur peminjalan alat. 


\section{DAFTAR PUSTAKA}

[1] Martono, A., Maulani, G., \& Pujianingsih, S. (2017). Pengembangan Web Alumni dengan Menggunakan Linkedin pada Perguruan Tinggi. Cyberpreneurship Innovative and Creative Exact and Social Science, 3(1), 71-83.

[2] Lazim, Farihin. Wijaya, Andi dan Arifin, Zainal (2016) Digital Inventory untuk Pendataan Barang Menggunakan Barcode di Laboratorium STT Nurul Jadid.Prosiding SENTIA.Vol 8.A311.

[3] Wijaya, T. (2017). Perancangan Middleware untuk Menghubungkan Sistem Informasi Dagang dengan Aplikasi e-Faktur dari Direktorat Jenderal Pajak. Creative Communication and Innovative Technology Journal, 10(1),35-45.

[4] Ependi, U. (2018). Pemodelan Sistem Informasi Monitoring Inventory Sekretariat Daerah Kabupaten Musi Banyuasin. Klik-Kumpulan Jurnal Ilmu Komputer, 5(1),49-60.

[5] Monalisa, S., Putra, E. D. P., \& Kurnia, F. (2018). Rancang Bangun Sistem Informasi Inventory Obat Pada Rumah Sakit Jiwa Tampan Berbasis Web. Query: Journal of Information Systems,2(2). 